\title{
A carbon nanotube-gemcitabine-lentinan three- component composite for chemo-photothermal synergistic therapy of cancer
}

This article was published in the following Dove Press journal: International Journal of Nanomedicine

\author{
Ping Zhang ${ }^{1,2}$ \\ Wenhui $Y^{1,2}$ \\ Jin $\mathrm{Hou}^{3}$ \\ Sweejiang Yoo ${ }^{1,2}$ \\ Weiqiu Jin ${ }^{1,2}$ \\ Qisheng Yang ${ }^{1,2}$ \\ 'Key Laboratory for Physical \\ Electronics and Devices of the \\ Ministry of Education, School \\ of Information and Electronics \\ Engineering, Xi'an Jiaotong University, \\ Xi'an, Shaanxi, People's Republic \\ of China; ${ }^{2}$ Key Laboratory for \\ Information Photonic Technology \\ of Shaanxi Province, School of \\ Information and Electronics \\ Engineering, Xi'an Jiaotong University, \\ Xi'an, Shaanxi, People's Republic of \\ China; ${ }^{3}$ Department of Pharmacology, \\ School of Basic Medical Sciences, \\ Xi'an Medical University, Xi'an, \\ Shaanxi, People's Republic of China
}

Correspondence: Wenhui $Y_{i}$ School of Information and Electronics Engineering, Xi'an Jiaotong University, Number 28 Xian Ning West Road, Xi'an, Shaanxi 7I 0049, People's

Republic of China

Tel/fax +86298262 6738

Email yiwenhui@mail.xjtu.edu.cn

Jin $\mathrm{Hou}$

School of Basic Medical Sciences, Xi'an Medical University, Number I Xin Wang Road, Xi'an, Shaanxi 7I002I, People's

Republic of China

Tel/fax +86298617 7562

Email II27538475@qq.com
Purpose: Gemcitabine's clinical application is limited due to its short plasma half-life and poor uptake by cells. To address this problem, a drug delivery three-component composite, multiwalled carbon nanotubes (MWNTs)/gemcitabine (Ge)/lentinan (Le; MWNTs-Ge-Le), was fabricated in our study. Moreover, the combination of chemotherapy and photothermal therapy was employed to enhance antitumor efficacy.

Methods: In this study, we conjugated gemcitabine and lentinan with MWNTs via a covalent and noncovalent way to functionalize with MWNTs, and the chemical structure of MWNTsGe-Le was characterized by Fourier transform infrared spectroscopy, Raman spectroscopy, thermogravimetric analysis and transmission electron microscopy. Using the composite and an $808 \mathrm{~nm}$ laser, we treated tumors, both in vitro and in vivo, and investigated the photothermal responses and the anticancer efficacy.

Results: The MWNTs-Ge-Le composite could efficiently cross cell membrane, having a higher antitumor activity than MWNTs, gemcitabine and MWNTs-Ge in vitro and in vivo. Our study on the MWNTs-Ge-Le composite with an $808 \mathrm{~nm}$ laser radiation showed the combination of drug therapy and near-infrared photothermal therapy possesses great synergistic antitumor efficacy.

Conclusion: The MWNTs-Ge-Le three-component anticancer composite can serve as a promising candidate for cancer therapy in the combination of chemotherapy and photothermal therapy.

Keywords: drug-containing nanocomposites, characterization, near-infrared radiation, cancer therapy

\section{Introduction}

Carbon nanomaterials, such as carbon nanotubes (CNTs), carbon nanodots and carbon nanohorns, have attracted particular interest in diverse research fields since their discoveries. ${ }^{1-3}$ Among them, CNTs hold a lot of attractive applications, particularly in the biomedical field, due to their unique components and shape. ${ }^{4-6}$ The properties of CNTs, such as high surface area-to-volume ratio, enable the CNTs to become a potential delivery tool for intracellular transport of components such as nucleic acids, proteins and drug molecules. ${ }^{7-9}$ In addition, the CNTs could passively penetrate and accumulate in tumor sites via their enhanced permeation and retention (EPR) effect. Furthermore, as the optical absorbance of CNTs in near-infrared (NIR) radiation region is quite strong, they are also considered as a kind of promising nanomaterial for developing the nextgeneration photothermal agents; ${ }^{10-12}$ of which, the optical absorbance in the biological window (700-1,400 $\mathrm{nm}$ ) can be utilized for cancer photothermal therapy. In addition, 
CNT-based targeted drug delivery vehicles have shown significant potential in the field of cancer therapy by combining chemotherapy with photothermal therapy. ${ }^{3,13-15}$ Multiwalled carbon nanotubes (MWNTs), which belong to one category of CNTs and have been employed in nanomedicine, are considered as an ideal mediator for chemo-photothermal combination therapy, since they have high drug-loading capacity and strong NIR radiation absorbance. ${ }^{16}$ Recently, our group reported that metformin loaded on MWNTs under NIR irradiation remarkably enhanced the response to cancer cells. ${ }^{17}$

However, the strong intertube van der Waals interaction has results in the MWNTs insoluble in aqueous solutions. ${ }^{18,19}$ Fortunately, MWNTs can be modified with many biological species, such as proteins ${ }^{20}$ and polysaccharides, ${ }^{21}$ giving the nanomaterial-wide biomedical applications. In recent years, natural polysaccharides such as schizophyllan, curdlan and lentinan have received tremendous attention due to their biocompatibility, nontoxicity and biodegradability. ${ }^{22-24}$ The study by Jia et $\mathrm{al}^{24}$ has revealed that the modified lentinan is a suitable dispersing agent for the MWNTs. As a kind of natural biological polysaccharide, lentinan has been widely investigated. ${ }^{25-27}$ Actually, as early as 1985, it has been clinically used for treating various cancers in conjunction with chemotherapy. ${ }^{25}$ The previous study by Sun et $\mathrm{al}^{28}$ has revealed that gemcitabine in combination with lentinan had synergistic effect, where the antitumor effect was remarkably enhanced.

Among the chemotherapeutic agents for cancer, nucleoside analogs are one of the most important classes of drugs. ${ }^{29}$ Gemcitabine, 2'-deoxy-2', 2'-difluorocytidine, an analog of deoxycytidine and S-phase-specific cell nucleoside, is a prototype of this class and inhibits ribonucleotide reductase. ${ }^{30}$ Therefore, it can resist several cancers including pancreatic, non-small-cell lung, breast and ovarian cancers. ${ }^{31}$ However, its clinical application is limited because of short plasma half-life and poor uptake by cells. ${ }^{32,33}$ In blood, the gemcitabine is rapidly deaminated into the inactive metabolite of $2^{\prime}, 2^{\prime}$-difluorodeoxyuridine, which is then quickly excreted through urine. ${ }^{34}$ To address this problem, over the past decade, nanoscience- and nanotechnology-based carriers have been widely explored in the field of drug delivery. ${ }^{35}$ In this study, a targeted drug delivery three-component composite, MWNTs/gemcitabine/lentinan (MWNTs-Ge-Le), was fabricated based on MWNTs that were functionalized with gemcitabine and lentinan to combine the advantages of those materials. The aim of this study was to explore the MWNTs-Ge-Le composite application potential in cancer therapy through combining chemotherapy and photothermal therapy.

\section{Materials and methods Materials}

MWNTs (purity $>95 \%$, length $<2 \mu \mathrm{m}$ ) were supplied by Nanjing XFNANO Materials Tech Co., Ltd. (Nanjing, China). Gemcitabine and lentinan were procured from Shanghai Puzhen Chemical reagent Co., Ltd. (Shanghai, China). All chemicals used are analytical reagent grade and were directly used without any further purification. Both 1-(3-dimethylaminopropyl)3 -ethylcarbodiimide (EDAC) and $N$-hydroxysulfosuccinimide (NHS) sodium salt were supplied by Adamas Reagent Co., Ltd. (Shanghai, China). CellMask Deep Red was purchased from Thermo Fisher Scientific (Waltham, MA, USA). Nitric acid and other reagents were commercially available and of analytical grade. Michigan cancer foundation-7 (Mcf-7) cells were obtained from Xi' an Medical College (Xi'an, China) and were approved by the laboratory animal ethics committee of Xi'an Medical College.

\section{Preparation and characterization of MWNTs-Ge-Le}

The details of the preparation of MWNTs-Ge-Le are clearly shown in Figure 1. For the grafting of gemcitabine, $35 \mathrm{mg}$ of MWNTs was first oxidized with the mixture of sulfuric acid and nitric acid (1:3 volume/volume) at $50^{\circ} \mathrm{C}$ to introduce the abundance of carboxylic functional groups. Subsequently, oxidized MWNTs (MWNTs-COOH) were washed and re-dispersed in $50 \mathrm{~mL}$ phosphate-buffered solution (PBS). Afterwards, the solution was treated with the addition of $100 \mathrm{mg}$ of gemcitabine, $180 \mu \mathrm{L}$ of EDAC and $0.2 \mathrm{~g}$ of NHS at room temperature to trigger the amidation process and then stirred for $24 \mathrm{~h}$. The reactant was washed, collected and recorded as MWNTs-Ge. The MWNTs-Ge was re-dispersed in $30 \mathrm{~mL}$ of lentinan solution $\left(1 \mathrm{mg} \cdot \mathrm{mL}^{-1}\right)$ under the aid of ultrasonic bath at $50^{\circ} \mathrm{C}$ for $1 \mathrm{~h}$ and followed by tip sonication $(200 \mathrm{~W}, 2 \mathrm{~h})$. The mixed liquid was filtered and washed to remove excess lentinan. Finally, the remaining solid was dried thoroughly and recorded as MWNTs-Ge-Le.

Fourier transform infrared (FT-IR) spectroscopy spectra of MWNTs-Ge-Le were acquired by an FT-IR spectrometer (Vertex 70; Bruker Corporation, Billerica, MA, USA), while Raman spectra were obtained by a confocal laser Raman spectrometer (HR 800; Horiba, Ltd., Kyoto, Japan) at $633 \mathrm{~nm}$. Thermogravimetric analysis (TGA) was conducted using a thermogravimetric analyzer (STA449C; NETZSCHGerätebau $\mathrm{GmbH}$, Selb, Germany), for which the samples were heated from room temperature to $1,400^{\circ} \mathrm{C}$ at the heating rate of $10^{\circ} \mathrm{C} / \mathrm{min}$ under nitrogen atmosphere. In addition, the transmission electron microscope (TEM) analysis was completed with a TEM JEM-2100 (JEOL, Tokyo, Japan). 

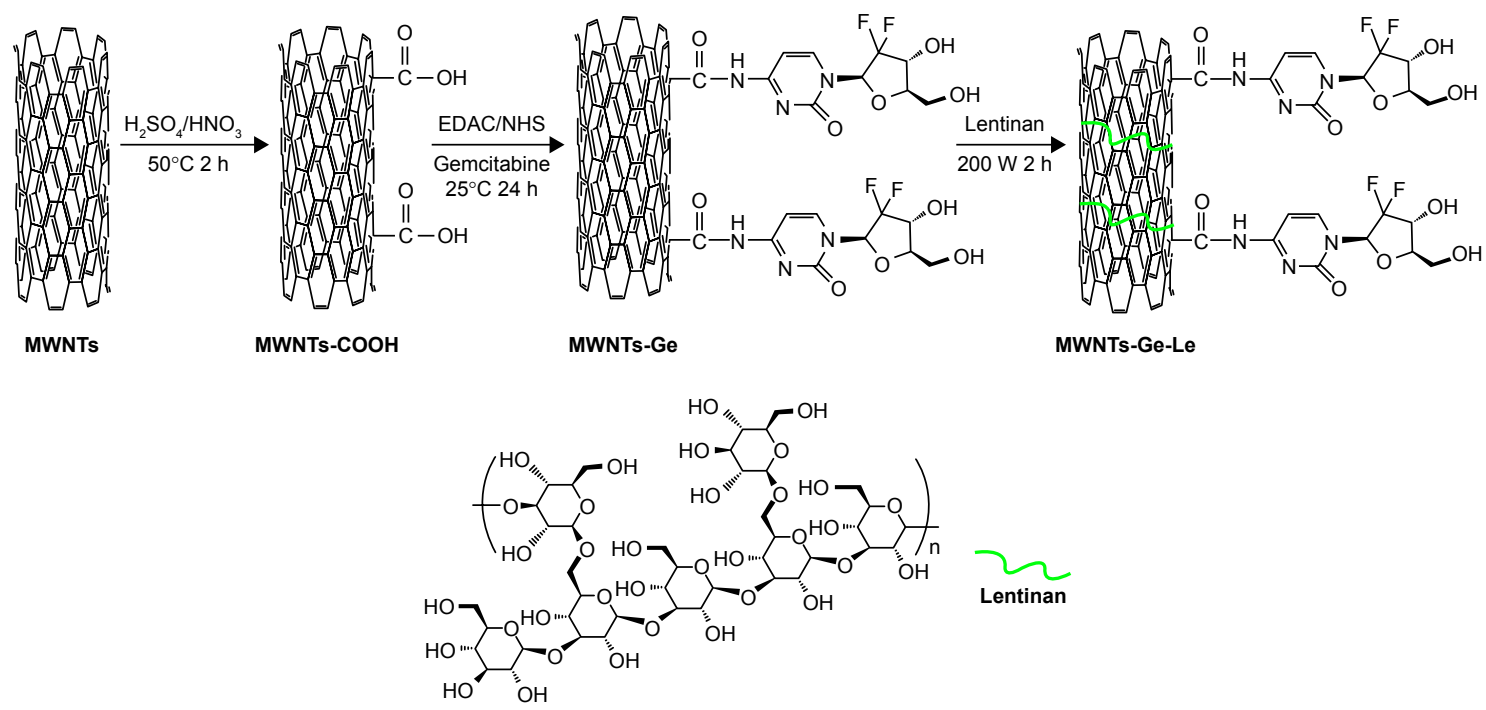

Figure I The approach for preparing MWNTs-Ge-Le.

Abbreviations: EDAC, I-(3-dimethylaminopropyl)-3-ethylcarbodiimide; MWNTs, multiwalled carbon nanotubes; MWNTs-COOH, oxidized multiwalled carbon nanotubes; MWNTs-Ge, multiwalled carbon nanotubes/gemcitabine; MWNTs-Ge-Le, multiwalled carbon nanotubes/gemcitabine/lentinan; NHS, N-hydroxysulfosuccinimide.

\section{Ex vitro measurement of heating of MWNTs-Ge-Le solution by NIR radiation}

The MWNTs-Ge-Le solutions were irradiated by $808 \mathrm{~nm}$ NIR laser at $0.5 \mathrm{~W} \cdot \mathrm{cm}^{-2}$; the power density was tunable up to $2 \mathrm{~W} \cdot \mathrm{cm}^{-2}$. During the irradiation, the laser was directed perpendicularly to the cell along the $Z$-axis direction; then, the temperature elevation was measured by the Omega with thermocouple and data-logging system (OMEGA Engineering, Inc., Norwalk, CT, USA).

\section{Confocal imaging and cellular uptake}

Mcf-7 cells were cultured in DMEM which had been supplemented with constituents of $10 \%$ fetal bovine serum and $1 \%$ penicillin-streptomycin. The incubations of MWNTs-Ge-Le with Mcf-7 cells were performed on $3.5 \mathrm{~mm}$ plates. Before adding MWNTs-Ge-Le, the cells had been seeded for $24 \mathrm{~h}$. Then, the incubations were performed under condition of $37^{\circ} \mathrm{C}$ and $5 \% \mathrm{CO}_{2}$ for $24 \mathrm{~h}$. Afterward, the CellMask Deep Red was added, and the cells were washed with PBS for three times. Scanning confocal fluorescence microscope was used to acquire the image of the cells.

\section{3-(4,5-Dimethylthiazol-2-yl)-2,5- diphenyltetrazolium bromide (MTT) cell proliferation assay}

The Mcf-7 cells were first suspended in DMEM and then were plated into 96-well plates at a density of $1 \times 10^{5}$ cells/ well. About $24 \mathrm{~h}$ later, the medium was replaced with DMEM in the presence or absence of complex (gemcitabine,
MWNTs, MWNTs-Ge and MWNTs-Ge-Le) for another $24 \mathrm{~h}$ and, then, irradiated by laser for $5 \mathrm{~min}\left(808 \mathrm{~nm}, 2 \mathrm{~W} \cdot \mathrm{cm}^{-2}\right)$. Finally, a cell proliferation assay kit of MTT was used to determine the viability of Mcf-7 cells.

\section{Animal model and treatment}

Healthy female BALB/c nude mice at the age of 6 weeks weighing 20-24 g were supplied by Experimental Animal Center of Xi' an Jiaotong University. All care and treatments applied to the mice involved in the very study complied with the Guide for the Care and Use of Laboratory Animals. All animal experiments were approved by the laboratory animal ethics committee of Xi' an Jiaotong University. Mcf-7 tumorbearing model was generated by subcutaneous injection of $2 \times 10^{6} \mathrm{Mcf}-7$ cells in $0.2 \mathrm{~mL}$ of PBS into either flank of mice. The mice were treated after the volume of tumor reached to $80 \mathrm{~mm}^{3}$ (14 days after tumor inoculation).

Mcf-7 tumor-bearing mice were divided into 10 groups: 1) PBS (controls); 2) gemcitabine; 3) MWNTs; 4) MWNTs-Ge; 5) MWNTs-Ge-Le; 6) PBS-laser; 7) gemcitabine-laser; 8) MWNTs-laser; 9) MWNTs-Ge-laser; 10) MWNTs-Ge-Lelaser. The injection of gemcitabine was given with normalized dose of $1.5 \mathrm{mg} \cdot \mathrm{kg}^{-1}$. After that, the clinical symptoms of mice were monitored daily and the size of tumor was measured by caliper every 3 days. The tumor volume was estimated by the formula $\mathrm{ab}^{2} / 2$, where a and $\mathrm{b}$ separately stand for the length and width of tumor, respectively.

For the treatment, the mice were intraperitoneally injected with different preparations every 3 days. After six times of such injection, the mice were euthanized, then tissues from 
the organs of heart, liver, spleen, lung and kidney and the tumors were harvested and soaked in 4\% paraformaldehyde solution. After being embedded in paraffin and mounted on slides stained with hematoxylin and eosin (H\&E), the morphological changes of collected tissues were observed by a microscope. For the laser irradiation, the treatments and groups were the same as described above with the exception that $808 \mathrm{~nm}$ laser irradiation $\left(1 \mathrm{~W} \cdot \mathrm{cm}^{-2}\right)$ was performed toward the tumor site of Mcf-7 tumor-bearing mice for $3 \mathrm{~min}$ after each administration..

\section{Statistical analysis}

Quantitative data were shown as mean \pm SD and analyzed with unpaired $t$-tests. The statistical analysis was completed by SPSS 16.0 software (SPSS Inc., Chicago, IL, USA), and the $P$-value of $<0.05$ was considered significant.

\section{Results and discussion}

\section{Preparation and characterization of} MWNTs-Ge-Le

The chemical structure of MWNTs-Ge-Le was characterized by FT-IR spectra as shown in Figure 2A. The spectra show a relatively strong absorption peak of MWNTs-COOH at 1,715 and $3,424 \mathrm{~cm}^{-1}$ which are respectively attributed to stretching vibration of $\mathrm{C}=\mathrm{O}$ and $\mathrm{O}-\mathrm{H}$ on the carboxyl group that was introduced for linkage purpose by the acidic oxidation treatment. For MWNTs-Ge, the peak at $1,715 \mathrm{~cm}^{-1}$ for the carboxyl group were almost diminished and the peak at $1,632 \mathrm{~cm}^{-1}$ for primary amine became intensified, indicating that the amide linkage of $(-[\mathrm{C}=\mathrm{O}] \mathrm{NH}-)$ was formed ${ }^{13,17}$ via an EDAC/NHS activation reaction. The peak at $1,041 \mathrm{~cm}^{-1}$ was identified as $\mathrm{C}-\mathrm{F}$ and $\mathrm{C}-\mathrm{O}-\mathrm{C}$ stretching vibrations, which also indicated that MWNTs were successfully modified with gemcitabine.

To obtain a further interpretation on the surface modification of MWNTs, Raman spectroscopy was performed (Figure 2B). The $\mathrm{I}_{\mathrm{D}} / \mathrm{I}_{\mathrm{G}}$ (intensity of D-band/intensity of G-band) ratios for MWNTs-COOH, MWNTs-Ge and MWNTs-Ge-Le were $0.65,0.98$ and 1.01 , respectively. Relative to the tangential mode, G-band, the intensity of D-band was significantly increased after covalent attachment of a gemcitabine molecule to a preexisting carboxylate group on MWNTs. The increase in the relative intensity of the disorder mode can be attributed to an increased number of $\mathrm{sp}^{3}$-hybridized carbons in the framework of MWNTs and can be taken as a crude measure of the degree of functionalization. ${ }^{36,37}$ According to our previous research, the observed upshifting of G-band peak for MWNTs-Ge-Le compared with MWNTs-COOH and
MWNTs-Ge can be confirmed to be attributed to the successful absorption of lentinan on the nanotube. ${ }^{17}$ However, the $\mathrm{I}_{\mathrm{D}}$ ' $\mathrm{I}_{\mathrm{G}}$ ratio had no obvious difference between MWNTs-Ge and MWNTs-Ge-Le, suggesting that the wrapping of lentinan on MWNTs-Ge by physical adhesion did not lead to any detectable damage of the structure of MWNTs-Ge.

As shown in Figure 2C, the drug-loading capability of MWNTs-Ge-Le has been quantified by the technique of TGA. From the results, it was found that the weight loss and the increase in mass introduced to the nanotubes at each step were directly correlated. Furthermore, it was indicated that the MWNTs were stable at the temperature of up to $675^{\circ} \mathrm{C}$, while the decomposition rate of pure gemcitabine and lentinan was very slow after $600^{\circ} \mathrm{C}$. At $600^{\circ} \mathrm{C}$, the weight loss of MWNTs, gemcitabine, lentinan, MWNTs-Ge and MWNTs-Ge-Le was 3.1\%, 67.5\%, 73.9\%, 27.1\% and $34.8 \%$, respectively. Hence, the drug-loading efficiency of gemcitabine and lentinan content in MWNTs-Ge-Le was estimated to be about $31.8 \%$ and $10.4 \%$, respectively.

In this study, temperature changes of MWNTs-Ge-Le were measured with an $808 \mathrm{~nm}$ laser. As shown in Figure 2D, heating efficiency of MWNTs-Ge-Le highly depends on power density, the irradiation time and the expected dose. The temperature of $25 \mu \mathrm{g} \cdot \mathrm{mL}^{-1} \mathrm{MWNT}-\mathrm{Ge}-L e$ solution increased from $25^{\circ} \mathrm{C}$ to $45^{\circ} \mathrm{C}$ under $2 \mathrm{~W} \cdot \mathrm{cm}^{-2} \mathrm{NIR}$ irradiation for $10 \mathrm{~min}$, whereas the temperature of pure water showed only a small increase at the same condition. Apparently, MWNTsGe-Le had strong light-heat conversion characteristics under laser irradiation at $808 \mathrm{~nm}$ and was adequate to induce strong localized heating and cell cytotoxicity.

The TEM images (Figure 2E) demonstrate that the nanotubes were coated with lentinan, which is in accordance with the data of FT-IR and Raman. The MWNTs-Ge-Le was soluble in water $\left(200 \mathrm{mg} \cdot \mathrm{mL}^{-1}\right)$, and the dispersion obtained remained stable after 6 months (inset is shown in Figure 2E). To understand the potential role of lentinan conformation in the MWNT wrapping, we performed a molecular modeling study which revealed that lentinan adopted a helical conformation (Figure 2F). Lentinan chains wrapped on the hydrophobic MWNTs surface to introduce steric repulsion and act as the barriers against the interaction between nanotubes, endowing MWNTs-Ge-Le good solubility in aqueous solution.

\section{Cellular uptake}

To confirm whether MWNTs-Ge-Le could enter into tumor cells, the MWNTs-Ge-Le was functionalized with rhodamine 123, a fluorescent tag, and then the emission fluorescence 
A

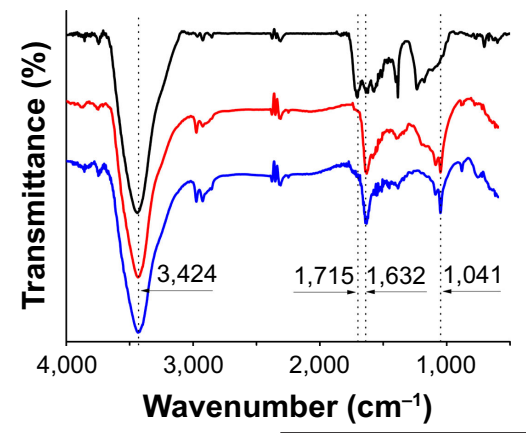

B

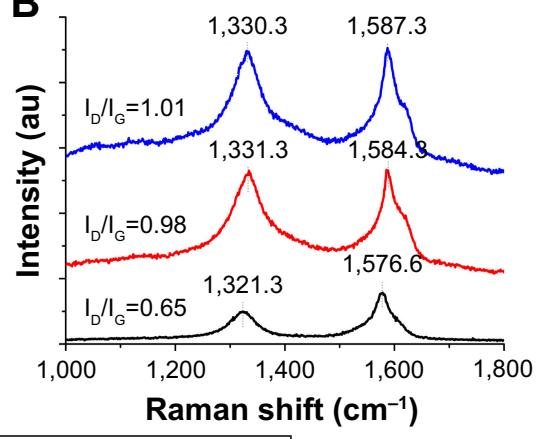

- MWNTs-COOH - MWNTs-Ge - MWNTs-Ge-Le

C

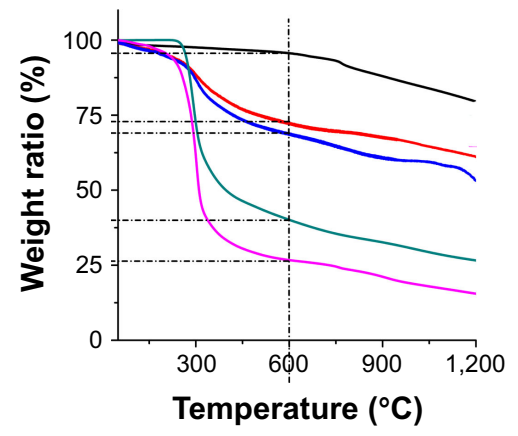

D

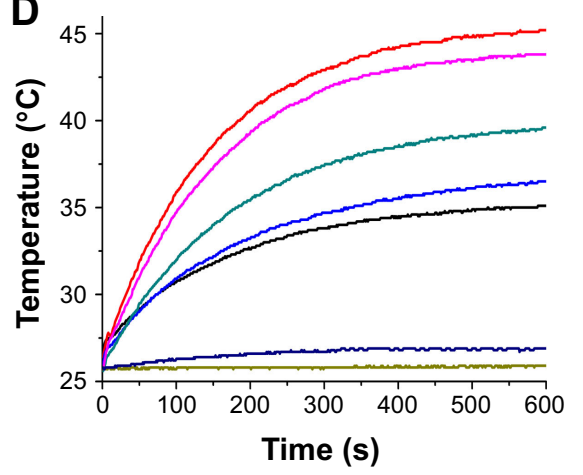

Time (s)
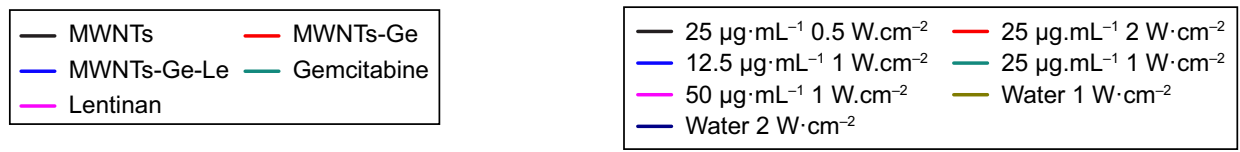

E

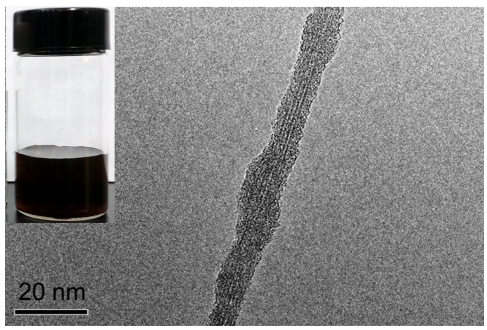

$\mathbf{F}$

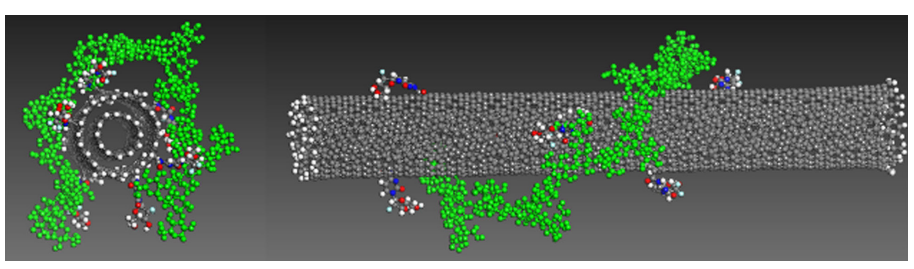

Average binding energy: $\sim 1,702 \mathrm{KJ} \cdot \mathrm{mol}^{-1}$

Figure 2 Characterization of MWNTs-Ge-Le.

Notes: (A) FT-IR spectra of MWNTs-COOH, MWNTs-Ge and MWNTs-Ge-Le. (B) Raman spectra of MWNTs-COOH, MWNTs-Ge and MWNTs-Ge-Le. (C) TGA curves of pristine MWNTs, MWNTs-Ge, MWNTs-Ge-Le, gemcitabine and lentinan. (D) Photothermal response of MWNTs-Ge-Le under various concentrations ( $\left(\mu \mathrm{g} \cdot \mathrm{mL}^{-1}\right)$ and $\mathrm{NIR}$ power density. The photothermal response is concentration and power dependent. (E) TEM images of MWNTs-Ge-Le. The inset is the photograph of MWNTs-Ge-Le after 6 months. (F) Molecular modeling of lentinan (green color) wrapped on a MWNTs-Ge using Materials Studio. Five repeat units were used to construct the lentinan. The binding energy, $E_{\text {binding }}=E_{\text {total }}\left(E_{\text {lentinan }}+E_{M W N T s-G e}\right)$, where $E_{\text {total }}$ is the total energy of the composite, $E_{\text {lentinan }}$ is the energy of the lentinan without the nanotube and $E_{\text {MWNTs-Ge }}$ is the energy of the nanotube without lentinan wrapping. Top view (left); front view (right).

Abbreviations: FT-IR, Fourier transform infrared; MWNTs, multiwalled carbon nanotubes; MWNTs-COOH, oxidized multiwalled carbon nanotubes; MWNTs-Ge, multiwalled carbon nanotubes/gemcitabine; MWNTs-Ge-Le, multiwalled carbon nanotubes/gemcitabine/lentinan; NIR, near-infrared; TEM, transmission electron microscope; TGA, thermogravimetric analysis.

from the tumor cell incubated with multiwalled carbon nanotubes/gemcitabine/lentinan/rhodamine 123 (MWNTsGe-Le-Rh) was observed. With the application of confocal microscopy imaging (Figure 3), it was found that the MWNTs-Ge-Le-Rh was internalized inside the cells within $3 \mathrm{~h}$ after incubation, once exposed to Mcf-7 cells. It showed that the cell membrane was stained with CellMask Deep
Red, whereas the green color conformed to the fluorescence labeling from rhodamine 123 on MWNTs. This study clearly proved that the MWNTs-Ge-Le-Rh penetrated into the cell membrane under the applied conditions. More importantly, as a unique quasi-one-dimensional material, MWNTs can deliver drug molecules into tumor cells, which compares well with the previous report by us. ${ }^{17}$ 

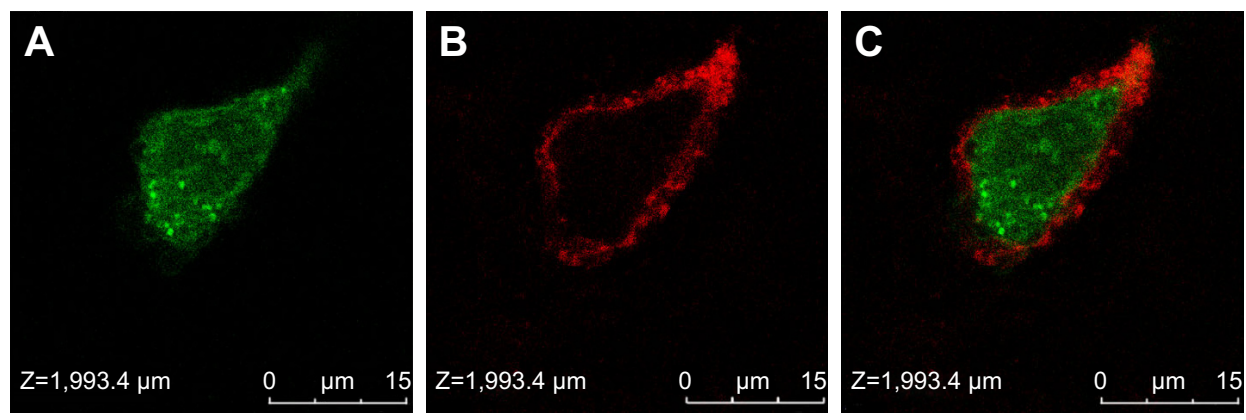

Figure 3 Laser confocal microscope images of Mcf-7 cells with MWNTs-Ge-Le-Rh.

Notes: (A) Rhodamine 123, (B) cell membrane staining by CellMask Deep Red, (C) overlay. The nanotubes were found internalized and accumulated inside the cell about $3 \mathrm{~h}$ after incubation.

Abbreviations: Mcf-7, Michigan cancer foundation-7; MWNTs-Ge-Le-Rh, multiwalled carbon nanotubes/gemcitabine/lentinan/rhodamine I23.

\section{In vitro cytotoxicity assay}

The cytotoxicity of gemcitabine, MWNTs, MWNTs-Ge and MWNTs-Ge-Le toward Mcf-7 cells under NIR irradiation $\left(2 \mathrm{~W} \cdot \mathrm{cm}^{-2}\right)$ was studied using MTT assay. As shown in Figure 4A, MWNTs-Ge and MWNTs-Ge-Le composites had lower cell viability than the same concentration of gemcitabine alone. For instance, the cell viability of MWNTs-Ge and MWNTs-Ge-Le containing $20 \mu \mathrm{g} \cdot \mathrm{mL}^{-1}$ of gemcitabine was $\sim 54.1 \%$ and $\sim 34.9 \%$, significantly lower than that of gemcitabine at the same concentration in the Mcf-7 cells $(\sim 64.0 \%)$. In general, effective cellular uptake leads to strong cytotoxicity. In addition, due to hydrophilic nature, gemcitabine cannot traverse cell membranes by passive diffusion, leading to poor uptake by cells. ${ }^{35}$ Therefore, effective delivery of gemcitabine was required to transport into the cells by an active transport process. Intriguingly, functionalized MWNTs were found to traverse the cell membrane passively or by translocation mechanism that was known as nanoneedle mechanism, which can enrich cellular uptake. ${ }^{38}$ Moreover, our confocal microscopy imaging experiment has proved that MWNTs-Ge-Le could carry gemcitabine molecules into Mcf-7 cells. Hence, the higher cytotoxicity effects of the composites could be attributed to enhanced nanoparticle-mediated cellular delivery of gemcitabine, demonstrating that the formulation of MWNTs of gemcitabine is a useful option for improving therapeutic effectiveness of gemcitabine.

In addition, both MWNTs-Ge and MWNTs-Ge-Le had dose-dependent anti-proliferation effects. The cell viability was decreased with the increase in the concentration of gemcitabine. Mcf-7 cells were treated with MWNTs-Ge at the concentrations of gemcitabine 5, 10 and $20 \mu \mathrm{g} \cdot \mathrm{mL}^{-1}$. The average cell viability was $79.1 \%, 69.1 \%$ and $54.1 \%$, respectively. While, after being treated with MWNTs-Ge-Le, given the same levels of drug concentration, cell viability was decreased to $59.2 \%, 48.9 \%$ and $34.9 \%$. Notably, the rapid decline of cell viability of Mcf-7 cells with MWNTsGe-Le compared with MWNTs-Ge indicated that the anti-proliferation effect on Mcf-7 human breast cancer cells of MWNTs-Ge-Le was better than that of MWNTs-Ge. The increased antitumor activities of MWNTs-Ge-Le were attributed to the unique properties of lentinan. On the one hand, lentinan can significantly enhance the antitumor activity of gemcitabine by stimulating natural killer group 2 member $D$ (NKG2D) and DNAX-associated protein 10/protein kinase B signaling pathway to activate natural killer (NK) cells..$^{39,40}$ The NKG2D upregulation could improve the sensitivity of NK-92 cells targeting to its ligand MHC class I-related chain A (MICA) expressed on cancer cells. At the same time, gemcitabine upregulated MICA expression and attenuated soluble MICA secretion through inhibiting disintegrin and metalloproteinase domain-containing protein 10 expression, which in turn enhanced the cytotoxicity of NK-92 cells against cancer cells. On the other hand, the conjugation of lentinan enhanced the uptake of MWNTs and significantly increased the concentration of gemcitabine inside cells, which finally enhanced the cytotoxicity. This might be because the functionalization with lentinan increased the individualization of MWNTs or increased the hydrodynamic radius of MWNTs, which played an important role in cellular uptake. ${ }^{38}$

Finally, the synergetic effect of gemcitabine and MWNTs was accessed under irradiation by NIR laser. As shown in Figure 4A, with NIR irradiation, tumor cell-killing potency of MWNTs-Ge had higher enhancement than that of gemcitabine and MWNTs alone. For example, at a gemcitabine concentration of $20 \mu \mathrm{g} \cdot \mathrm{mL}^{-1}$, the inhibition rate of MWNTs-Ge with NIR irradiation was $\sim 89.6 \%$, while the inhibition rate of free gemcitabine and MWNTs was $37.0 \%$ and $73.2 \%$, 


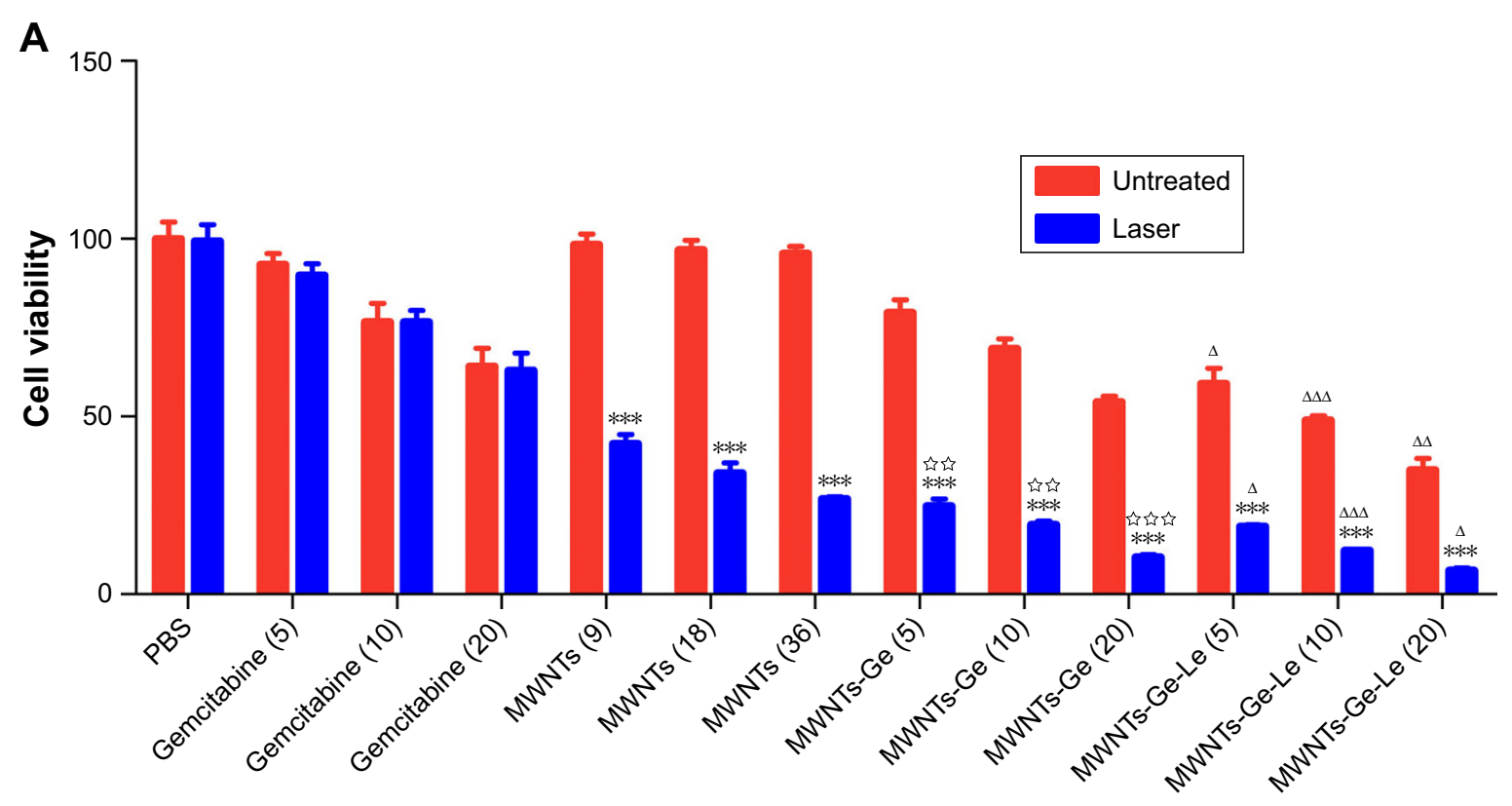

B

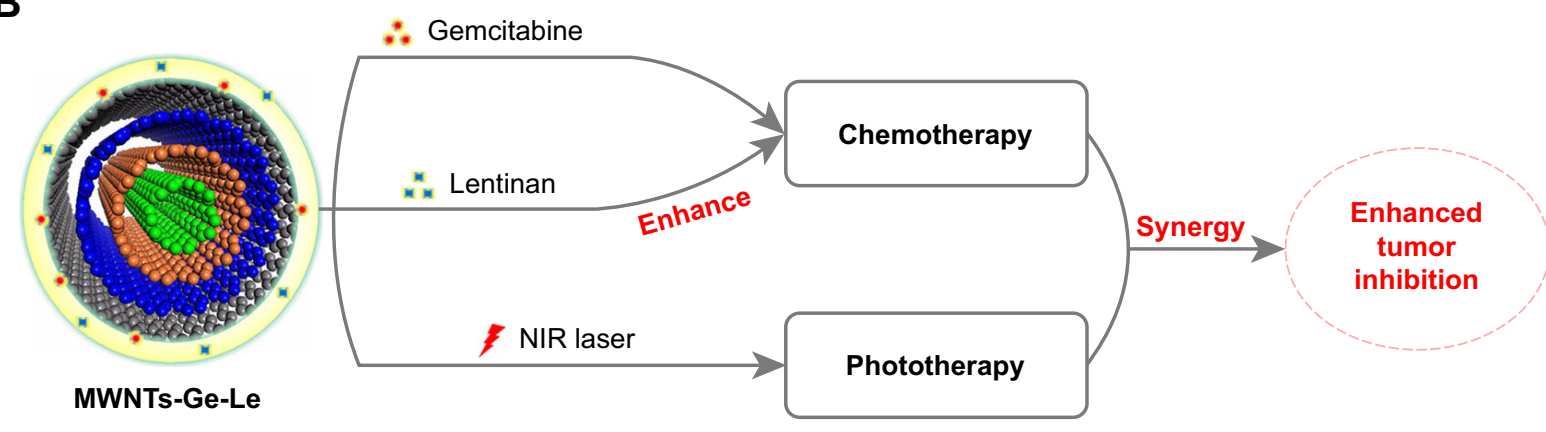

Figure 4 The cell viabilities of Mcf-7 cells incubated with gemcitabine, MWNTs, MWNTs-Ge and MWNTs-Ge-Le under NIR irradiation were established via MTT assay (A) and schematic illustration of the chemo-photothermal combined cancer therapy under $808 \mathrm{~nm}$ NIR laser irradiation of MWNTs-Ge-Le composite (B).

Notes: Gemcitabine (5), MWNTs-Ge (5) and MWNTs-Ge-Le (5) had the same concentration of gemcitabine (5 $\left.\mu \mathrm{g} \cdot \mathrm{mL}^{-1}\right)$. Gemcitabine (10), MWNTs-Ge (I0) and MWNTsGe-Le (10) had the same concentration of gemcitabine $\left(10 \mu \mathrm{g} \cdot \mathrm{mL}^{-1}\right)$. Gemcitabine (20), MWNTs-Ge (20) and MWNTs-Ge-Le (20) had the same concentration of gemcitabine $\left(20 \mu \mathrm{g} \cdot \mathrm{mL}^{-1}\right)$. The NIR irradiation power density was $2 \mathrm{~W} \cdot \mathrm{cm}^{-2}(5 \mathrm{~min})$. The bars are presented as the mean \pm SEM (unpaired $t$-test; $* * * P<0.00 \mathrm{I}$ compared with without NIR irradiation; $\triangle P<0.05, \Delta P P<0.01$ and $\triangle \Delta P<0.001$ compared with the relative MWNTs-Ge-treated group; ${ }^{\star \star P} P<0.01$ and ${ }^{\star \star \star} P<0.001$ compared with the relative MWNTs and gemcitabine treated groups).

Abbreviations: Mcf-7, Michigan cancer foundation-7; MWNTs, multiwalled carbon nanotubes; MWNTs-Ge, multiwalled carbon nanotubes/gemcitabine; MWNTs-Ge-Le, multiwalled carbon nanotubes/gemcitabine/lentinan; MTT, 3-(4,5-dimethylthiazol-2-yl)-2,5-diphenyltetrazolium bromide; NIR, near-infrared; PBS, phosphate-buffered solution; SEM, standard error of the mean.

respectively, indicating an enhanced cell-killing effect. In addition, tumor cell-killing potency was enhanced when MWNTs-Ge was combined with NIR irradiation compared with MWNTs-Ge without NIR irradiation. For example, the inhibition rate of Mcf-7 cells with MWNTs-Ge upon NIR irradiation at a gemcitabine concentration of $20 \mu \mathrm{g} \cdot \mathrm{mL}^{-1}$ was $43.7 \%$ higher than that of MWNTs-Ge without NIR irradiation. Therefore, the synergistic effect of MWNTs-Ge with NIR is remarkable. In addition, the synergistic effect of chemo-thermal therapy can be calculated according to the additive therapeutic efficiency $\left(\mathrm{T}_{\text {add }}\right)$ of tumor cells as an evaluation index. ${ }^{41}$ The additive therapeutic efficacies of chemotherapy and photothermal therapy alone were calculated by applying the formula (Equation 1), where f stands for the proportion of surviving cells after every treatment. ${ }^{42}$

$$
\mathrm{T}_{\text {add }}=100-\left(\mathrm{f}_{\text {chem }} \times \mathrm{f}_{\text {photo }}\right) \times 100
$$

According to Figure $4 \mathrm{~A}$, at the $20 \mu \mathrm{g} \cdot \mathrm{mL}^{-1}$ gemcitabine concentration, the Mcf-7 cells treated with gemcitabine $\left(\mathrm{f}_{\text {chem }}\right)$ and MWNTs plus NIR irradiation ( $\left.\mathrm{f}_{\text {photo }}\right)$ exhibited cell viability up to $\sim 62.9 \%$ and $\sim 26.7 \%$, respectively. The calculated additive value of $\mathrm{T}_{\text {add }}$ was $\sim 82.3 \%$, which was higher than the sole chemotherapy (37.1\%) or photothermal 
therapy $(73.3 \%)$, but significantly lower than the measured therapeutic efficacy of the MWNTs-Ge with laser irradiation ( $\sim 89.6 \%)$. The results verified that the MWNTs-Ge possessed an obvious synergistic effect for the combined chemo-photothermal therapy, which brought a high therapeutic efficacy.

Figure 4A shows that MWNTs-Ge-Le combined with NIR irradiation achieves the best cell inhibition effect among all the groups tested in our experiments. As illustrated in Figure 4B, it combines the advantages of: 1) the outstanding properties of lentinan, 2) the high synergetic effect of chemotherapy and photothermal therapy. Therefore, it can significantly enhance tumor inhibition effect.

\section{Antitumor activity of MWNT delivery system in vivo under $808 \mathrm{~nm}$ laser irradiation}

Encouraged by the aforementioned results in vitro, we then proceeded to estimate the synergistic antitumor efficiency of MWNTs-Ge-Le on tumor-bearing mice. In this study, the low power density and short NIR irradiation time $\left(1 \mathrm{~W} \cdot \mathrm{cm}^{-2}\right.$, $3 \mathrm{~min}$ ) were employed in in vivo experiments. We measured the tumor surface temperature after intraperitoneal injection and subsequent NIR irradiation time. Compared with intratumoral injection, the model of intraperitoneal administration has better clinical relevance. As shown in Figure 5A, the temperature of tumors surface was slightly lower than that of abdomen before NIR irradiation treatment. However, after 3 min of NIR irradiation treatment in tumor site, the temperature of the tumor surface increased rapidly. As expected, among all the groups, the temperature of tumor site treated with MWNTs-Ge-Le had the biggest increase, because of the highest accumulation of MWNTsGe-Le nanoparticles at the tumor site through EPR effect. The temperature of tumor site treated with MWNTs-Ge-Le increased to approximately $42.6^{\circ} \mathrm{C}$ after NIR irradiation, while the temperature of tumor site treated with PBS only increased to about $36.6^{\circ} \mathrm{C}$ at the same time.
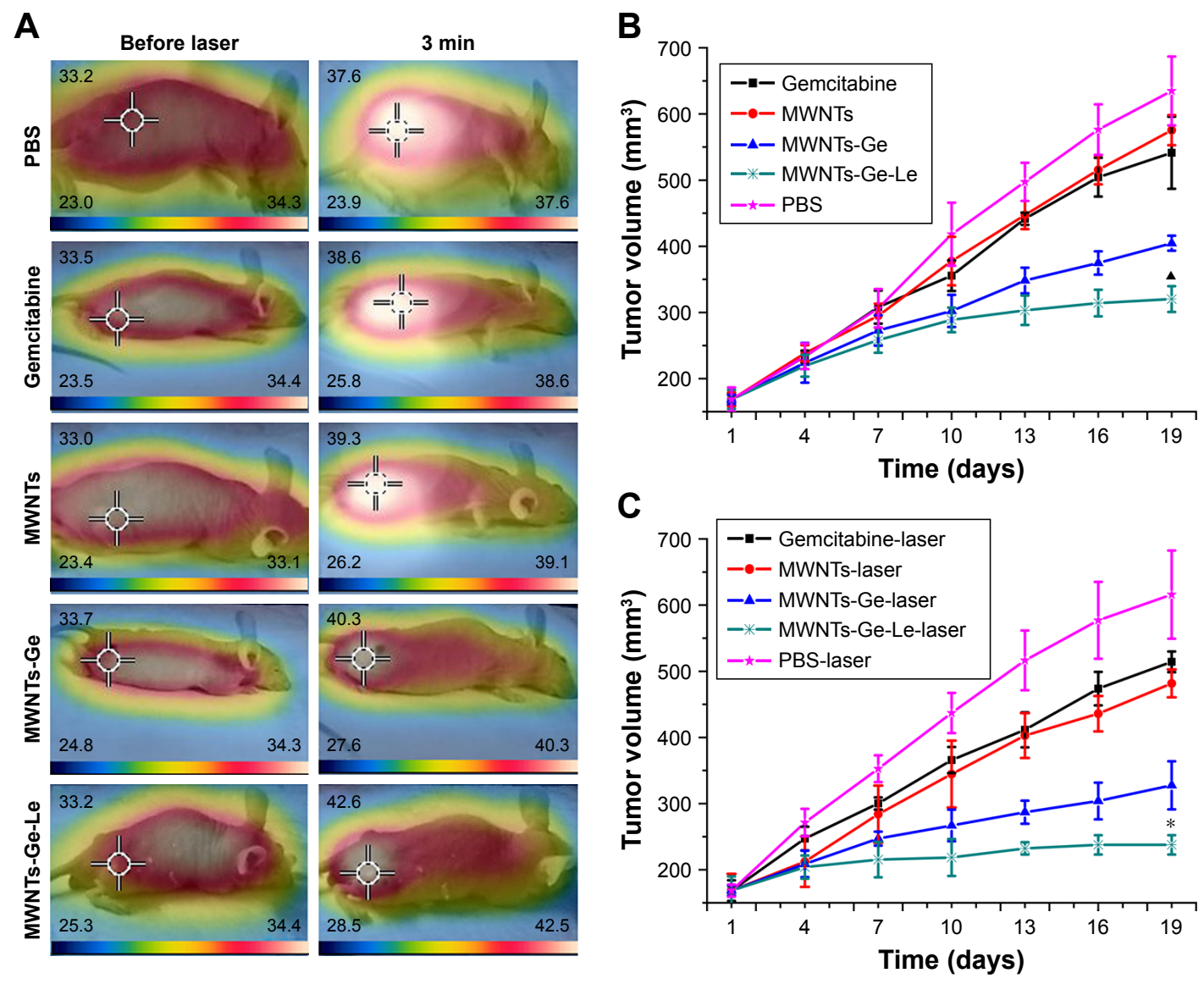

Figure 5 In vivo antitumor effect.

Notes: (A) Infrared thermographic images of tumor-bearing mice after treatment with PBS, gemcitabine, MWNTs, MWNTs-Ge and MWNTs-Ge-Le followed by laser irradiation. The scale bar is different for each image. (B) Average tumor volume in a Mcf-7 tumor-bearing mice model of treatment without laser in vivo. (C) Average tumor volume in a Mcf-7 tumor-bearing mice model of treatment with laser in vivo. The relative tumor volumes were normalized to their initial size ( $n=4$ for each group). The bars are presented as mean \pm SEM (unpaired t-test, $* P<0.05$ compared with all the other experimental groups; ${ }^{\wedge} P<0.05$ compared with PBS group, gemcitabine group, MWNTs group and MWNTs-Ge group). Abbreviations: Mcf-7, Michigan cancer foundation-7; MWNTs, multiwalled carbon nanotubes; MWNTs-Ge, multiwalled carbon nanotubes/gemcitabine; MWNTs-Ge-Le, multiwalled carbon nanotubes/gemcitabine/lentinan; NIR, near-infrared; PBS, phosphate-buffered solution; SEM, standard error of the mean. 
The antitumor effect was observed over a period of 19 days with the results as shown in Figure 5. The results without laser irradiation experiment (Figure 5B) showed remarkable decrease in tumor size in the MWNTs-Ge and MWNTs-Ge-Le groups, in comparison with the normal PBS group, gemcitabine group or MWNTs group. More importantly, at equivalent gemcitabine doses, we observed that MWNTs-Ge-Le significantly reduced the tumor growth than MWNTs-Ge did $(P<0.05)$. This observation is according to the in vitro cytotoxicity results. Previous studies show that polysaccharide-based nanoparticles may prolong the in vivo residence time of nanoparticles and increase the possibility of tumor site accumulation. ${ }^{43}$ Thus, the reasons why MWNTs-Ge-Le group has higher efficacy in vivo than MWNTs-Ge group might be because the increased ability of cellular uptake, the enhanced blood circulation time and improved ability of penetrating via EPR effect.

After being irradiated by laser, the size of tumor in all tested groups was found to be decreased in comparison with the normal PBS group without irradiation. But there was no significant difference between the PBS and PBS-laser groups or gemcitabine and gemcitabine-laser groups, indicating that laser irradiation inhibited tumor growth through MWNTs. Remarkably, it was found that the MWNTs-Ge-Le-laser group, among all tested groups, showed the strongest antitumor activity, including in the early stage of treatment, confirming the outstanding properties of lentinan and high synergetic effect of chemotherapy and photothermal therapy in vivo. Intriguingly, in the previous study, PEGylated singlewalled CNTs/gemcitabine composites were used for suppressing tumor growth in B6 nude mice and showed strong inhibitory effect; ${ }^{44}$ however, a larger dose of gemcitabine $\left(25 \mathrm{mg} \cdot \mathrm{kg}^{-1}\right)$ was generally required for a sufficient treatment efficacy. In the study, the treatment efficacy was achieved with the administration of only $1.5 \mathrm{mg} \cdot \mathrm{kg}^{-1}$ gemcitabine. The main reasons are attributed to the high MWNTs-Ge-Le accumulation in tumor tissue and the good ability of NIR laser to penetrate the body. Thus, the combination of chemotherapy and photothermal therapy has been proved to be more effective in cancer treatments, which is significantly superior to individual chemotherapy or photothermal therapy.

It has to be noted that the temperature elevation at tumor site treated with MWNTs-Ge-Le and NIR irradiation was lower than the most reported study in vivo.,14 However, the in vivo results showed that MWNTs-Ge-Le with NIR irradiation had strong antitumor activity, suggesting that the hyperthermia efficacy of MWNTs-Ge-Le with the low power density and short NIR irradiation time $\left(1 \mathrm{~W} \cdot \mathrm{cm}^{-2}\right.$, $3 \mathrm{~min}$ ) was sufficient to kill cancer cells and to reduce the risk of damaging the normal cells and tissues. The previous in vivo studies have proved that the maximum thermal enhancement of cytotoxicity of many chemotherapeutic agents was at mild temperatures $\left(40.5^{\circ} \mathrm{C}-43^{\circ} \mathrm{C}\right) .^{45} \mathrm{In}$ addition, hyperthermia, mild heating to about $40.5^{\circ} \mathrm{C}-43^{\circ} \mathrm{C}$, has been employed as an adjunctive therapeutic mode of tumor together with chemotherapy, ${ }^{1}$ by which the cellular metabolism and membrane permeability that can enhance the drug uptake by cells are increased. ${ }^{46}$ Furthermore, local hyperthermia has the advantage which reduces damage to normal tissues while heating up the tumor. In this study, the local temperature was raised by the use of hyperthermia to enhance drug uptake by tumor cells. Thus, although the elevations of tumor temperature are less effective as monotherapy against cancer, it has potent efficacy when combined with chemotherapy.

To further prove the photothermal effect of MWNTsGe-Le, we measured the temperature changes after intratumoral injection, the same dose, of MWNTs-Ge-Le under the same irradiation condition of intraperitoneal injection. As shown in Figure 6, for the MWNTs-Ge-Le-injected mice, the surface temperature of tumor was dramatically increased within just 3 min to $63.8^{\circ} \mathrm{C}$, which is significantly higher than the maximum temperature that cancer cells can tolerate. However, the tumor surface temperature of PBS-injected mice was just increased to $37.9^{\circ} \mathrm{C}$. This result indicates that even a lower dose of chemotherapy can lead to a greater anticancer effect using the MWNTs-Ge-Le composite. Overall, the MWNTs-Ge-Le three-component composite has exhibited a strong anticancer efficacy and has emerged as a great prospect for clinical application by combining chemotherapy with photothermal therapy.

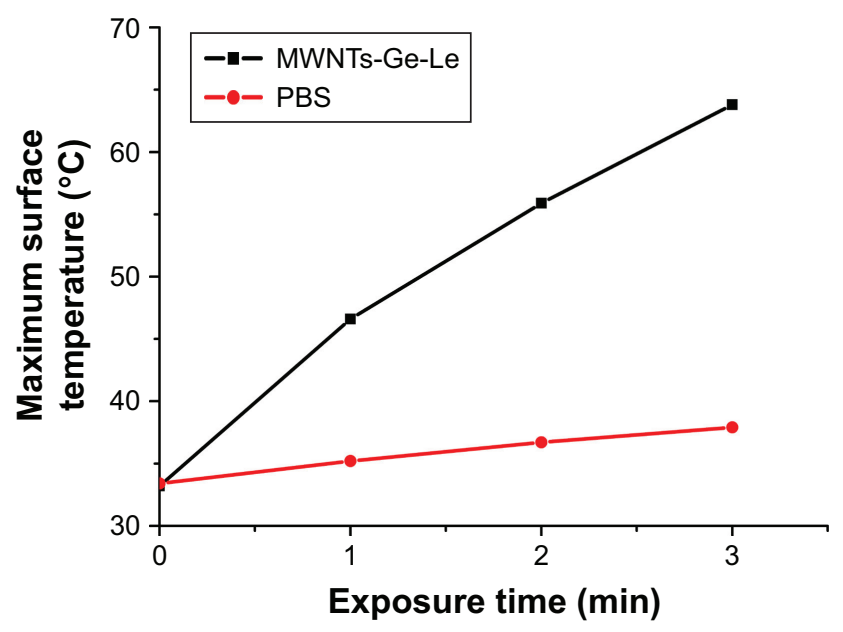

Figure 6 Plots of tumor surface temperature increase after intratumoral injection and subsequent NIR irradiation $\left(808 \mathrm{~nm}, \mathrm{I} \mathrm{W} \cdot \mathrm{cm}^{-2}\right)$.

Abbreviations: MWNTs-Ge-Le, multiwalled carbon nanotubes/gemcitabine/lentinan; PBS, phosphate-buffered solution; NIR, near-infrared. 


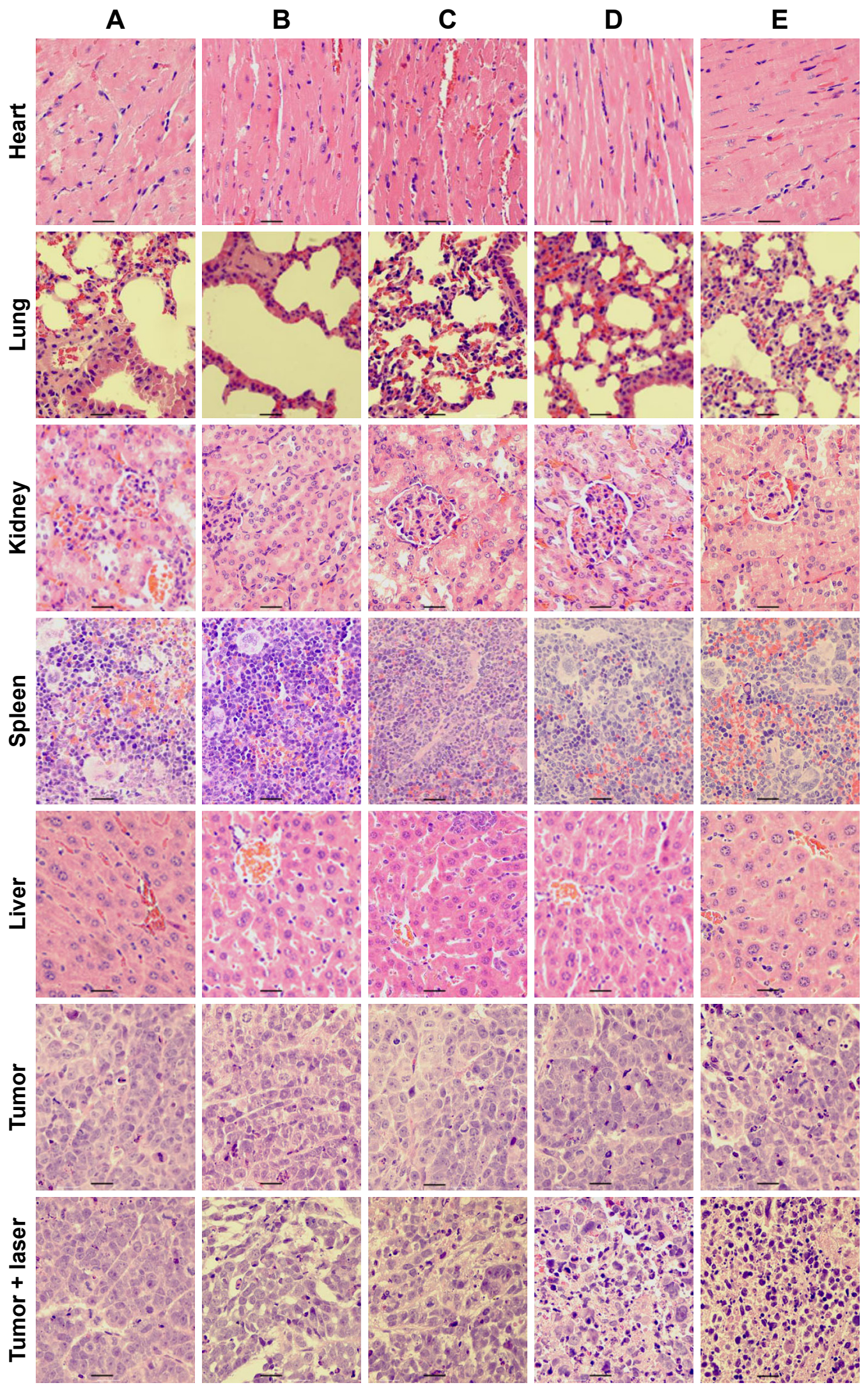

Figure 7 Histologic assessments of major organs and tumor tissues with H\&E staining in mice.

Notes: (A) PBS, (B) gemcitabine, (C) MWNTs, (D) MWNTs-Ge, (E) MWNTs-Ge-Le. Bar $=10 \mu \mathrm{m}$.

Abbreviations: H\&E, hematoxylin and eosin; MWNTs, multiwalled carbon nanotubes; MWNTs-Ge, multiwalled carbon nanotubes/gemcitabine; MWNTs-Ge-Le, multiwalled carbon nanotubes/gemcitabine/lentinan; PBS, phosphate-buffered solution. 


\section{Histological analysis}

To explore the effect of MWNTs-Ge-Le on the organs of mice, a histological assay was conducted covering all major organs of heart, liver, spleen, lung, kidney and tumor with paraffinembedded sections and staining of H\&E (Figure 7). The results showed that all the major organs were found to have no significant toxicity in comparison with the control group (PBS group); however, evident difference was detected in tumor histology. In the control group, tumor cells exhibited vigorous growth with tighter arrangement, larger body and intact shape. However, cell concentration, necrosis, lysis, and fragmentation occurred to a certain extent in the MWNTs-laser, MWNTs-Gelaser and MWNTs-Ge-Le-laser groups. Particularly, among all the tested groups, such phenomena were most apparent for the MWNTs-Ge-Le-laser groups. These histological results further verified the fact that the combination therapy based on MWNTs-Ge-Le with NIR irradiation was in possession of the most excellent inhibition effect of tumor growth in vivo. Therefore, the combination therapy demonstrates promising application potential in cancer therapy.

\section{Conclusion}

In this study, we have demonstrated the successful synthesis of MWNTs-Ge-Le three-component anticancer composite by chemical functionalization. The formation of this functionalized MWNTs was supported by FT-IR, Raman spectrum, TGA and TEM. The MWNTs-Ge-Le composite possessed the features, which were introduced by gemcitabine, lentinan and MWNTs, such as good antitumor activity, biocompatibility, hydrophilicity and extraordinary photothermal properties. Most importantly, because of the outstanding properties of lentinan and the high synergetic effect of chemotherapy and photothermal therapy, the MWNTs-Ge-Le with NIR irradiation had the highest tumor inhibition effect among all the groups tested in vitro and in vivo. Furthermore, in vivo results showed that localized hyperthermia from MWNTs combined with chemotherapeutic drug enabled the composite to effectively kill cancer cells and reduced the risk of hurting the normal cells and tissues. However, further investigations are still expected before its clinical application.

\section{Acknowledgments}

This research was generously supported by the Natural Science Foundation of China (numbers 61275179 and 60970815), the Natural Science Basic Research Plan in Shaanxi Province of China (program number 2016JM8047), the Fundamental Funds for the Central Universities (number xjj2015112), and the Shaanxi Province Administration of Traditional Chinese Medicine (15-ZY036).

\section{Author contributions}

WY, JH and PZ conceived and designed the research. PZ wrote the paper. PZ, SY, WJ and QY worked on material synthesis and analysis. PZ and $\mathrm{JH}$ designed and performed the antitumor activity experiments in vitro and in vivo. WY managed the research team. All authors contributed toward data analysis, drafting and critically revising the paper and agree to be accountable for all aspects of the work.

\section{Disclosure}

The authors report no conflicts of interest in this work.

\section{References}

1. Chen D, Wang C, Jiang F, Liu Z, Shu C, Wan L. In vitro and in vivo photothermally enhanced chemotherapy by single-walled carbon nanohorns as a drug delivery system. J Mater Chem B. 2014;2(29):4726-4732.

2. Nguyen V, Si J, Yan L, Hou X. Electron-hole recombination dynamics in carbon nanodots. Carbon N Y. 2015;95:659-663.

3. Zhang L, Rong P, Chen M, Gao S, Zhu L. A novel single walled carbon nanotube (SWCNT) functionalization agent facilitating in vivo combined chemo/thermo therapy. Nanoscale. 2015;7(39):16204-16213.

4. Mahmood M, Karmakar A, Fejleh A, et al. Synergistic enhancement of cancer therapy using a combination of carbon nanotubes and anti-tumor drug. Nanomedicine. 2009;4(8):883-893.

5. Siu KS, Chen D, Zheng X, et al. Non-covalently functionalized singlewalled carbon nanotube for topical siRNA delivery into melanoma. Biomaterials. 2014;35(10):3435-3442.

6. Liang C, Diao S, Wang C, et al. Tumor metastasis inhibition by imagingguided photothermal therapy with single-walled carbon nanotubes. Adv Mater. 2014;26(32):5646-5652.

7. Mielcarek J, Skupin P. [Functionalization of carbon nanotubes for multimodal drug delivery] Funkcjonalizacja nanorurek weglowych jako potencjalnych nosnikow lekow. Przegl Lek. 2011;68(3):167-170. Polish.

8. Chen J, Chen S, Zhao X, Kuznetsova LV, Wong SS, Ojima I. Functionalized single-walled carbon nanotubes as rationally designed vehicles for tumor-targeted drug delivery. J Am Chem Soc. 2008;130(49): 16778-16785.

9. Chen Q, Wang Q, Liu Y, et al. Energetics investigation on encapsulation of protein/peptide drugs in carbon nanotubes. J Chem Phys. 2009; 131(1):0151011

10. Oh Y, Jin J, Oh J. Photothermal-triggered control of sub-cellular drug accumulation using doxorubicin-loaded single-walled carbon nanotubes for the effective killing of human breast cancer cells. Nanotechnology. 2017;28(12):125101.

11. Xu Y, Heberlein WE, Mahmood M, et al. Progress in materials for thermal ablation of cancer cells. J Mater Chem. 2012;22(38):20128-20142.

12. Singh R, Torti SV. Carbon nanotubes in hyperthermia therapy. Adv Drug Deliv Rev. 2013;65(15):2045-2060.

13. Wang L, Shi J, Zhang H, et al. Synergistic anticancer effect of RNAi and photothermal therapy mediated by functionalized single-walled carbon nanotubes. Biomaterials. 2013;34(1):262-274.

14. Dong X, Sun ZT, Wang XX, Leng XG. An innovative MWCNTs/ DOX/TC nanosystem for chemo-photothermal combination therapy of cancer. Nanomedicine. 2017;13(7):2271-2280.

15. Zhou M, Liu S, Jiang Y, et al. Doxorubicin-loaded single wall nanotube thermo-sensitive hydrogel for gastric cancer chemo-photothermal therapy. Adv Funct Mater. 2015;25(29):4730-4739. 
16. Sarkar S, Gurjarpadhye AA, Rylander CG, Rylander MN. Optical properties of breast tumor phantoms containing carbon nanotubes and nanohorns. J Biomed Opt. 2011;16(5):0513045.

17. Yoo S, Hou J, Yi W, et al. Enhanced response of metformin towards the cancer cells due to synergism with multi-walled carbon nanotubes in photothermal therapy. Sci Rep. 2017;7(1):1071.

18. Wu H, Chang X, Liu L, Zhao F, Zhao Y. Chemistry of carbon nanotubes in biomedical applications. J Mater Chem. 2010;20(6):1036-1052.

19. Laverny G, Casset A, Purohit A, et al. Immunomodulatory properties of multi-walled carbon nanotubes in peripheral blood mononuclear cells from healthy subjects and allergic patients. Toxicol Lett. 2013; 217(2):91-101.

20. Versiani AF, Astigarraga RG, Rocha ESO, et al. Multi-walled carbon nanotubes functionalized with recombinant Dengue virus 3 envelope proteins induce significant and specific immune responses in mice. J Nanobiotechnology. 2017;15(1):26.

21. Rajesh R, Dominic Ravichandran Y, Jeevan Kumar Reddy M, Ryu SH, Shanmugharaj AM. Development of functionalized multi-walled carbon nanotube-based polysaccharide-hydroxyapatite scaffolds for bone tissue engineering. RSC Adv. 2016;6(85):82385-82393.

22. Star A, Steuerman DW, Heath JR, Stoddart JF. Starched carbon nanotubes. Angew Chem Int Edit. 2002;41(14):2508.

23. Numata M, Asai M, Kaneko K, et al. Inclusion of cut and as-grown single-walled carbon nanotubes in the helical superstructure of schizophyllan and curdlan (ss-1,3-glucans). J Am Chem Soc. 2005;127(16): 5875-5884.

24. Jia X, Chen P, Xu X, Zhang L. Lentinan greatly enhances the dispersibility of single-walled carbon nanotubes in water and decreases the cytotoxicity. Bioactive Carbohydrates Dietary Fibre. 2013;1(2):111-119.

25. Xing J, Liu Z, Huang Y, et al. Lentinan-modified carbon nanotubes as an antigen delivery system modulate immune response in vitro and in vivo. ACS Appl Mater Interfaces. 2016;8(30):19276-19283.

26. Tamura R, Tanebe K, Kawanishi C, Torii K, Ono T. Effects of lentinan on abnormal ingestive behaviors induced by tumor necrosis factor. Physiol Behav. 1997;61(3):399-410.

27. Maeda YY, Lentinan CG. A new immuno-accelerator of cell-mediated responses. Nature. 1971;229(5287):634.

28. Sun M, Zhao W, Xie Q, Zhan Y, Wu B. Lentinan reduces tumor progression by enhancing gemcitabine chemotherapy in urothelial bladder cancer. Surg Oncol. 2015;24(1):28-34.

29. Jordheim LP, Durantel D, Zoulim F, Dumontet C. Advances in the development of nucleoside and nucleotide analogues for cancer and viral diseases. Nat Rev Drug Discov. 2013;12(6):447-464.

30. Guo Z, Gallo JM. Selective protection of 2', 2'-difluorodeoxycytidine (gemcitabine). J Org Chem. 1999;64(22):8319-8322.

31. Moysan E, Bastiat G, Benoit J. Gemcitabine versus modified gemcitabine: a review of several promising chemical modifications. $\mathrm{Mol}$ Pharm. 2013;10(2):430-444.
32. Hamsici S, Sardan Ekiz M, Cinar Ciftci G, Tekinay AB, Guler MO. Gemcitabine integrated nano-prodrug carrier system. Bioconjug Chem. 2017;28(5):1491-1498.

33. Joubert F, Martin L, Perrier S, Pasparakis G. Development of a gemcitabine-polymer conjugate with prolonged cytotoxicity against a pancreatic cancer cell line. ACS Macro Lett. 2017;6(5):535-540.

34. Han H, Wang H, Chen Y, et al. Theranostic reduction-sensitive gemcitabine prodrug micelles for near-infrared imaging and pancreatic cancer therapy. Nanoscale. 2016;8(1):283-291.

35. Dubey RD, Saneja A, Gupta PK, Gupta PN. Recent advances in drug delivery strategies for improved therapeutic efficacy of gemcitabine. Eur J Pharm Sci. 2016;93:147-162.

36. Bahr JL, Tour JM. Highly functionalized carbon nanotubes using in situ generated diazonium compounds. Chem Mater. 2001;13(11): $3823-3824$

37. Tian R, Wang X, Li M, et al. An efficient route to functionalize singewalled carbon nanotubes using alcohols. Appl Surf Sci. 2008;255(5): 3294-3299.

38. Lacerda L, Russier J, Pastorin G, et al. Translocation mechanisms of chemically functionalised carbon nanotubes across plasma membranes. Biomaterials. 2012;33(11):3334-3343.

39. Xie X, Zhou Y, Wang X, et al. Enhanced antitumor activity of gemcitabine by polysaccharide-induced NK cell activation and immune cytotoxicity reduction in vitro/vivo. Carbohydr Polym. 2017;173:360-371.

40. Takeda K, Okumura K. CAM and NK cells. Evid Based Compl Alt. 2004;1(1):17-27.

41. Liu Y, Zhang X, Liu Z, et al. Gold nanoshell-based betulinic acid liposomes for synergistic chemo-photothermal therapy. Nanomedicine. 2017;13(6):1891-1900.

42. Park H, Yang J, Lee J, Haam S, Choi I, Yoo K. Multifunctional nanoparticles for combined doxorubicin and photothermal treatments. ACS Nano. 2009;3(10):2919-2926.

43. Swierczewska M, Han HS, Kim K, Park JH, Lee S. Polysaccharidebased nanoparticles for theranostic nanomedicine. Adv Drug Deliver Rev. 2016;99:70-84.

44. Razzazan A, Atyabi F, Kazemi B, Dinarvand R. In vivo drug delivery of gemcitabine with PEGylated single-walled carbon nanotubes. $\mathrm{Mat} \mathrm{Sci}$ Eng C Mater Biol Appl. 2016;62:614-625.

45. Chatterjee DK, Diagaradjane P, Krishnan S. Nanoparticle-mediated hyperthermia in cancer therapy. Ther Deliv. 2011;2(8):1001-1014.

46. Shen P, Hawksworth J, Lovato J, et al. Cytoreductive surgery and intraperitoneal hyperthermic chemotherapy with mitomycin c for peritoneal carcinomatosis from nonappendiceal colorectal carcinoma. Ann Surg Oncol. 2004;11(2):178-186.
International Journal of Nanomedicine

\section{Publish your work in this journal}

The International Journal of Nanomedicine is an international, peerreviewed journal focusing on the application of nanotechnology in diagnostics, therapeutics, and drug delivery systems throughout the biomedical field. This journal is indexed on PubMed Central, MedLine, CAS, SciSearch $®$, Current Contents ${ }^{\circledR} /$ Clinical Medicine,
Dovepress

Journal Citation Reports/Science Edition, EMBase, Scopus and the Elsevier Bibliographic databases. The manuscript management system is completely online and includes a very quick and fair peer-review system, which is all easy to use. Visit http://www.dovepress.com/ testimonials.php to read real quotes from published authors. 